\title{
Cold Stratification and Pericarp Removal Improve Seed Germination of Ptelea trifoliata and Ptelea crenulata
}

\author{
Anna J. Talcott and William R. Graves \\ Department of Horticulture, Iowa State University, 106 Horticulture Hall, \\ Ames, IA 50011
}

Additional index words. dormancy, hoptree, polyethylene glycol, propagation, tetrazolium chloride, wafer ash

\begin{abstract}
Two species of North American shrubs in the genus Ptelea (Rutaceae), commonly known as eastern and western hoptree or wafer ash, have unfulfilled potential to increase the diversity of managed landscapes and support populations of pollinators and swallowtail butterflies. The white flowers of Ptelea are highly fragrant, and pistillate flowers give rise to clusters of distinctive samaras. The insufficiency of information about improving germination of seeds of Ptelea trifoliata and lack of recommendations for Ptelea crenulata prompted us to investigate effects of pericarp removal and cold $\left(4{ }^{\circ} \mathrm{C}\right)$ stratification periods of $0,4,8$, and 16 weeks on the germination of seeds of these two species. Samaras were collected from multiple plants of both species in the midwestern United States $(P$. trifoliata) and California $(P$. crenulata). The germination percentage of viable seeds, calculated after tests of viability with tetrazolium chloride of seeds that did not germinate, increased with longer stratification periods, with $100 \%$ germination for $P$. crenulata and $91 \%$ germination for $P$. trifoliata after 16 weeks of stratification. The germination value, a measure of the speed and uniformity of germination, and peak value also increased with longer stratification in both species. Pericarp removal increased the germination percentage of both species and increased the peak and germination value of $P$. crenulata. Propagators seeking to grow these species of Ptelea from seed should remove the pericarp and cold-stratify seeds for 16 weeks to improve germination success.
\end{abstract}

Ptelea trifoliata L. (Rutaceae) has been used as an ornamental shrub since the 18th century and has gained international favor in England and Scotland; however, it remains a rare choice among landscapers (Harvey, 1981; Lancaster, 1995). Two cultivars exist, 'Glauca', which has dark green leaves, and 'Aurea', which has golden leaves (Dirr, 1998). Horticultural attention has focused on P. trifoliata; however, the genus comprises two other species, Ptelea crenulata Greene and Ptelea aptera Parry (Yang and Applequist, 2015). Uncommonly used plants have the potential to add species diversity to landscapes, which can stabilize ecosystems (Tilman et al., 2006).

Ptelea trifoliata and P. crenulata are understory, shade-tolerant shrubs measuring 2 to $5 \mathrm{~m}$ in height with trifoliate leaves (Dirr, 1998; McMinn, 1989). The fruits are compressed samaras that are broadly winged,

Received for publication 1 Nov. 2019. Accepted for publication 9 Jan. 2020.

Published online 17 March 2020.

We thank Frank Balestri for help with seed collection, Michael Stahr and the Iowa State University Seed Laboratory for sharing equipment, and Christopher and Laura Yiesla for generous laboratory assistance.

A.J.T. is the corresponding author. E-mail: atalcott@ iastate.edu.

This is an open access article distributed under the CC BY-NC-ND license (https://creativecommons. org/licenses/by-nc-nd/4.0/). flowers form inflorescences that emit a strong, unique fragrance (Knuth, 1908; Kurz, 1997; McMinn, 1989; Nokes, 2001). Almost entirely dioecious, $P$. trifoliata blooms in late May to June, and $P$. crenulata blooms in April (Ambrose et al., 1985; Dirr, 1998).

Ptelea trifoliata comprises five subspecies that occur in much of North America from Ontario to Florida and as far west as Nebraska and Arizona (Bailey, 1962; Yang and Applequist, 2015). Ptelea crenulata is found in California and P. aptera is found in Baja California (Yang and Applequist, 2015). In Canada, 102 species of insects from 40 families visit $P$. trifoliata and are thought to be pollinators (Ambrose et al., 1985). Leaves are eaten by larvae of swallowtail butterflies and grasshoppers (Scriber and Dowell, 1991; Sword and Dopman, 1999). The larvae of the moths Agonopterix pteleae Barnes and Busck and Agonopterix costimacula Clarke feed exclusively on $P$. trifoliata in Illinois (Harrison and Berenbaum, 2005).

Several reports of the propagation of $P$. trifoliata from seeds are available (Dreesen and Harrington, 1997; McLeod and Murphy, 1977; USDA Forest Service, 1948). With 3 to 4 months of cold stratification, $28 \%$ germination was reported (USDA Forest Service, 1948). Other researchers who stratified seeds for 18 weeks found differences in germination based on samara size and color (Dreesen and Harrington, 1997). The highest germination $(50 \%)$ occurred among the large, greencolored samaras that had the proximal end removed (Dreesen and Harrington, 1997). Higher germination $(68 \%)$ was reported when seeds were excised from pericarp and stratified for $181 \mathrm{~d}$ (McLeod and Murphy, 1977). Samara leachate inhibited germination, implying a chemical inhibitor (McLeod
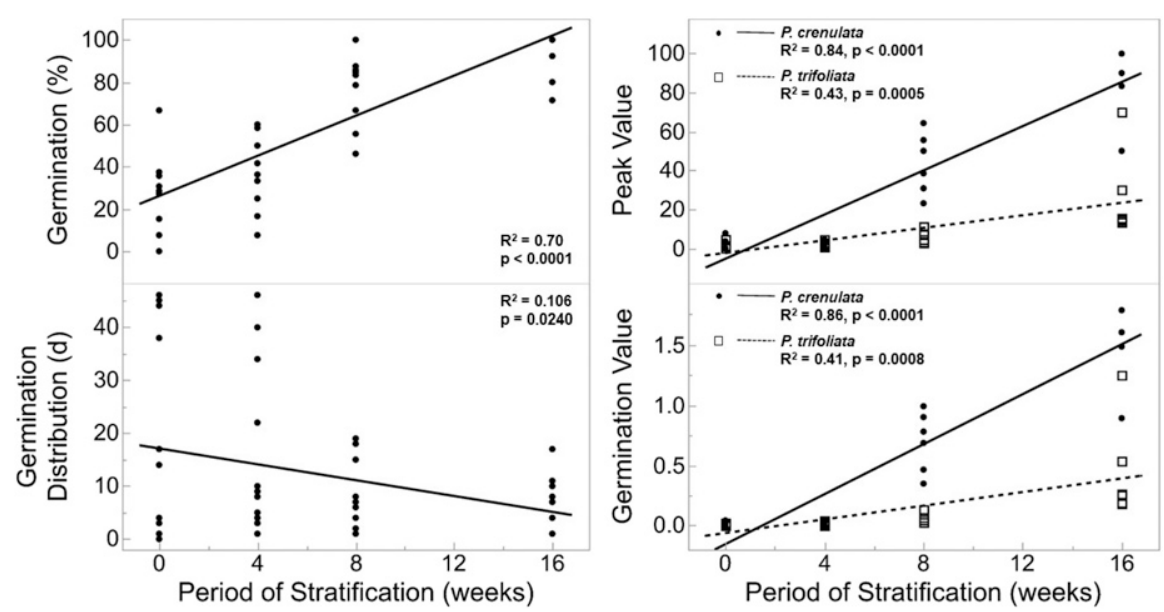

Fig. 1. Stratification period $(0,4,8$, and 12 weeks) affects germination (\%), germination distribution (d), peak value, and germination value of Ptelea crenulata and Ptelea trifoliata during Expt. 1. Peak value is defined as the cumulative germination percentage on the day of greatest germination divided by the number of days to reach that level, germination distribution is defined as the span of days between the first and last germinating seeds, and germination value is defined as peak value multiplied by the mean daily germination, which expresses completeness and rate of germination. Mean daily germination is defined as germination percentage per unit divided by number of days for germination. Species data were pooled and designated with black dots for the germination percentage and germination distribution because species were not significantly different from each other. A significant difference between $P$. crenulata (black circles and solid line) and P. trifoliata (open squares and dotted line) was observed only for peak value and germination value. 


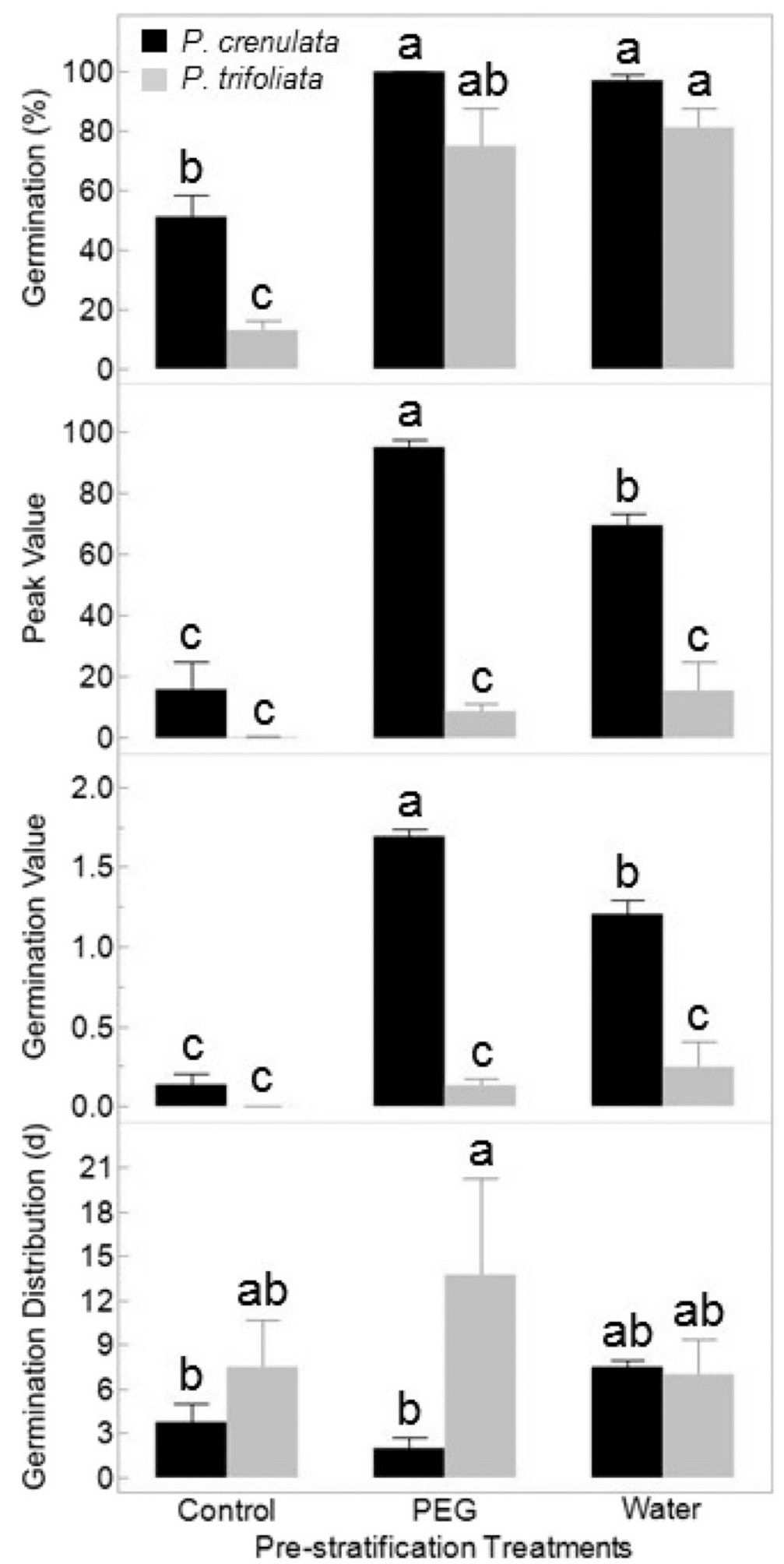

Fig. 2. During Expt. 2, the prestratification treatment groups were as follows: whole unsoaked samaras (control); seeds removed from softened pericarp after soaking overnight in water (water); and seeds removed from softened pericarp after soaking in polyethylene glycol 8000 solution $(-0.6 \mathrm{MPa}$; PEG). Bars represent means of germination (\%), peak value, and germination value of Ptelea crenulata (black) and Ptelea trifoliata (gray). Peak value is defined as the cumulative germination percentage on the day of greatest germination divided by the number of days to reach that level, germination distribution was defined as the span of days between the first and last germinating seeds, and germination value was defined as peak value multiplied by the mean daily germination, which expresses completeness and rate of germination. Mean daily germination is defined as germination percentage per unit divided by number of days for germination. Lowercase letters indicate mean separation among prestratification treatments by Tukey's honestly significant difference test at $P \leq 0.05$. All seeds were stratified for 16 weeks. and Murphy, 1977). Despite the previous attention to seed germination in $P$. trifoliata, the need for a more precise procedure exists, and there is no information about the germination of seeds of $P$. crenulata. Soaking seeds in water with dissolved polyethylene glycol (PEG), called osmopriming, has been used to increase the germination rates of various crops (Farooq et al., 2005; Naglreiter et al., 2005; Salehzade et al., 2009). PEG decreases the water potential difference between dry seeds and surrounding moisture. PEG is physiologically inert because its large molecular mass prevents it from entering cell membranes (Naglreiter et al., 2005). Rapid imbibition can lead to reduced cellular respiration and germination (Powell and Matthews, 1978); in theory, PEG should facilitate more gradual imbibition.

Our objective was to optimize the speed, uniformity, and completeness of germination of $P$. trifoliata and $P$. crenulata with stratification and pericarp removal. During our first experiment, the effects of stratification duration were compared with seeds that had been separated from their pericarps. During our second experiment, the effects of two methods of pericarp removal were compared with use of intact, whole samaras because it is not clear how McLeod and Murphy (1977) removed pericarps. Both our removal methods involved soaking samaras to soften the pericarp, but one was soaked in a PEG solution to determine if rapid imbibition had any effect on seed vitality.

\section{Materials and Methods}

Expt. 1: Stratification effects. Mature, dried samaras from four plants from a small population of $P$. crenulata from Black Diamond Mines Regional Preserve in Antioch, CA were collected with permission on 11 Sept. 2016. Mature, dried samaras from two cultivated plants of $P$. trifoliata were collected on 21 Sept. 2016 from the Morton Arboretum in Lisle, IL, where five hoptrees are present. These source plants had been grown from seeds collected in the wild along the Apple River in Jo Daviess County, IL, and Essex County, Ontario, Canada. After being softened by soaking in tap water for 12 to $24 \mathrm{~h}$, samara pericarps were torn in two by hand to remove the seeds. Seeds were stratified at $4{ }^{\circ} \mathrm{C}$ for $0,4,8$, and 16 weeks in damp sphagnum moss in petri dishes placed inside sealed plastic bags to retain moisture. The experimental unit of 20 seeds was replicated six times for each stratification period. For $P$. trifoliata, three replicates from each treatment contained seeds from two plant sources. For $P$. crenulata, all six replicates contained seeds from all four plant sources.

After stratification, seeds were transferred to damp blotting paper in clear plastic germination boxes $(10 \times 10 \times 4 \mathrm{~cm})$ kept inside a germination chamber set to $17{ }^{\circ} \mathrm{C}$ for 8-h photoperiods. Each germination box contained one experimental unit of seeds, 
and units were randomly arranged within the chamber. Germination, defined as radicle emergence, was recorded daily for $56 \mathrm{~d}$. Viability of ungerminated seeds was tested with tetrazolium chloride according to the guidelines for species of Rutaceae (Miller and Peters, 2010). All germination measurements were calculated based on the number of viable seeds, unless otherwise noted.

Germination percentage, mean daily germination (germination percentage per unit divided by the number of days for germination), peak day (day of most germination), peak value (cumulative germination percentage on the day of greatest germination divided by the number of days to reach that level), germination value (peak value multiplied by the mean daily germination, which expresses completeness and rate of germination), and germination distribution (the span of days between the first and last germinating seeds) were determined (Czabator, 1962). These measures were subjected to linear regression, and the viability percentage was compared using an analysis of variance (ANOVA) and Tukey's honestly significant difference test (JMP Pro 14 software; version 14, SAS Institute Inc., Cary, NC).

Expt. 2: Pre-stratification effects. Mature dried samaras were obtained in Sept. 2017, from the maternal sources used during the first experiment, as well as from additional plants of $P$. trifoliata from the Morton Arboretum from accessions from Essex County (Ontario, Canada) and Arbordale Nurseries (Getzville, NY). Three pre-stratification treatments were applied before stratifying all the seeds for 16 weeks at $4{ }^{\circ} \mathrm{C}$. The treatment groups were as follows: 1) whole unsoaked samaras (control group); 2) seeds removed from softened pericarp after soaking 12 to $24 \mathrm{~h}$ in tap water (water group); and 3) seeds removed from softened pericarp after soaking 12 to $24 \mathrm{~h}$ in PEG 8000 solution $(-0.6$ MPa; Michel et al., 1983). Germination conditions, procedures, and viability tests were the same as those used during the first experiment. An experimental unit of 24 seeds was replicated four times for each treatment and species combination. ANOVA were conducted for viability, germination value, percentage, distribution, peak day and value, and mean daily germination; means were separated using Tukey's honestly significant difference test as performed during the first experiment.

\section{Results}

During the first experiment, the germination percentage increased and germination distribution decreased as the period of stratification increased for both species (Fig. 1). After 16 weeks of cold stratification, $91 \%$ of the viable seeds of $P$. trifoliata and $100 \%$ of the viable seeds of $P$. crenulata germinated. Both the peak value and germination value of $P$. crenulata increased more rapidly than those of $P$. trifoliata as the period of stratification increased (Fig. 1). In an effort to eliminate any unnecessary variability, we included only viable seeds in Figs. 1 and 2. Table 1 includes combined nonviable and viable seeds for comparison. Viability was similar for both species and among stratification treatments during the first experiment and among prestratification treatments during the second (Table 1).

Pericarp removal improved the germination percentage in both species during the second experiment (Fig. 2). The combination of pericarp removal and soaking in PEG solution maximized peak and germination values in $P$. crenulata; however, increases in peak and germination values were not significant for $P$. trifoliata (Fig. 2). The germination distribution was shorter for $P$. crenulata than for $P$. trifoliata, but this difference was only significant with seeds soaked in PEG solution (Fig. 2). Although our data violate the assumptions of normality and equal variance, we consider these statistical tests to be robust enough to describe the data accurately.

\section{Discussion}

Seeds of both species should be stratified for 16 weeks after pericarp removal to increase the speed and completeness of germination. The use of PEG solution or water to soften and remove pericarps enhances the speed of germination for $P$. crenulata without reducing viability, although seeds soaked in PEG solution had faster speed than water alone. For both species, the removal of pericarps increases the percentage of seeds that ultimately germinate.

Stratifying seeds of both species for 16 weeks improves the speed and completeness of germination (Fig. 1). After 16 weeks of cold stratification, $91 \%$ of the viable seeds of P. trifoliata and $100 \%$ of the viable seeds of $P$. crenulata germinated, which are higher percentages than those previously reported (Fig. 1; McLeod and Murphy, 1977). Although it is unclear if McLeod and Murphy (1977) included nonviable seeds in their $68 \%$ germination result, they reported $85 \%$ to $100 \%$ viability; however, we observed $45 \%$ to $83 \%$ viability. Therefore, it seems best to compare their results with those of our viable seeds alone because of the variability in viability. Other researchers who reported $28 \%$ and $50 \%$ germination who did not report viability probably included nonviable seeds in the results, which is better for comparisons with our combined viable and nonviable results, which is $60 \%$ germination (Table 1, USDA Forest Service, 1948; Dreesen and Harrington, 1997). This improvement is likely induced by changes in method such as pericarp removal.

The use of water and especially of PEG solution to soften and remove pericarps improves the speed and uniformity of germination for $P$. crenulata; furthermore, for both species, removal of pericarps increases the total germination percentage (Fig. 2). As previously shown by McLeod and Murphy (1977), our results indicate that pericarp removal increases germination completeness (Fig. 2). Increasing stratification times even to $242 \mathrm{~d}$ without pericarp removal did not improve germination completeness (McLeod and Murphy, 1977). Soaking samaras softened the pericarp in such a way that the seed could be readily separated. The lower germination percentage reported by the USDA Forest Service (1948) might have been due to the use of seeds surrounded by intact pericarps. Dreesen and Harrington (1997) likely reduced the mechanical barrier of the pericarp by removing the proximal end of the samara, but these seeds still may have experienced chemical inhibition, as described by McLeod and Murphy (1977).

Seed viability was not reduced by longer stratification, by removal of pericarps, or by soaking in water or PEG (Table 1). Because it

Table 1. Combined viable and nonviable germination (\%) and viability (\%) of seeds of Ptelea crenulata and Ptelea trifoliata. ${ }^{2}$

\begin{tabular}{|c|c|c|c|c|}
\hline & \multicolumn{2}{|c|}{ Ptelea crenulata } & \multicolumn{2}{|c|}{ Ptelea trifoliata } \\
\hline & Germination (\%) & Viability (\%) & Germination (\%) & Viability (\%) \\
\hline 0 & $20 \mathrm{~A}^{\mathrm{y}}$ & $58 \mathrm{~A}$ & $12 \mathrm{~A}$ & $45 \mathrm{~A}$ \\
\hline 8 & $52 \mathrm{~B}$ & $58 \mathrm{~A}$ & $38 \mathrm{~B}$ & $51 \mathrm{~A}$ \\
\hline 16 & $60 \mathrm{~B}$ & $60 \mathrm{~A}$ & $45 \mathrm{~B}$ & $49 \mathrm{~A}$ \\
\hline \multicolumn{5}{|c|}{ Expt. 2: Prestratification treatments } \\
\hline Control & $40 \mathrm{a}^{\mathrm{x}}$ & $79 \mathrm{a}$ & $11 \mathrm{a}$ & $83 \mathrm{a}$ \\
\hline
\end{tabular}

${ }^{\mathrm{z}}$ During Expt. 1, seeds were stratified for 0, 4, 8, and 16 weeks. During Expt. 2, prestratification treatment groups were as follows: whole unsoaked samaras (control); seeds removed from softened pericarp after soaking in polyethylene glycol 8000 solution ( $-0.6 \mathrm{MPa}$; PEG); and seeds removed from softened pericarp after soaking in water (water).

${ }^{{ }^{y}}$ Uppercase letters in columns indicate mean separation among stratification periods by Tukey's honestly significant difference test at $P \leq 0.05$.

${ }^{x}$ Lowercase letters in columns indicate mean separation among prestratification treatments by Tukey's honestly significant difference test at $P \leq 0.05$. 
was not clear how pericarps were removed by McLeod and Murphy (1977), it was important to confirm that removal methods did not compromise viability. Soaking seeds in PEG solution, which has a lower water potential than water, could allow seeds to imbibe more slowly, but it is not necessary to improve seed viability as measured by the tetrazolium chloride test. Interestingly, when compared with water soaking, the PEG soaking treatment did increase the speed of germination in $P$. crenulata, suggesting that slowing imbibition did prevent some cellular damage. Powell and Matthews (1978) reported reduced respiration, increased electrolyte leakage, and incomplete tetrazolium chloride staining of pea embryos that had been soaked without testa and had imbibed more quickly than those with intact testa (Fig. 2).

To increase the speed, uniformity, and completeness of germination, propagators of either $P$. crenulata or $P$. trifoliata should stratify seeds for 16 weeks. For $P$. trifoliata, soaking in water and removal of pericarp before stratification are recommended to increase completeness of germination. For $P$. crenulata, soaking in a PEG 8000 solution would increase the speed and uniformity of germination compared with soaking in water.

\section{Literature Cited}

Ambrose, J.D., P.G. Kevan, and R.M. Gadawski. 1985. Hop tree (Ptelea trifoliata) in Canada: Population and reproductive biology of a rare species. Can. J. Bot. 63:1928-1935.

Bailey, V.L. 1962. Revision of the genus Ptelea (Rutaceae). Brittonia 14:1-45.
Czabator, F.J. 1962. Germination value: An index combining speed and completeness of pine seed germination. For. Sci. 8:386-396.

Dirr, M.A. 1998. Manual of woody landscape plants: Their identification, ornamental characteristics, culture, propagation, and uses. Stipes Publ., Champaign, IL.

Dreesen, D.R. and J.T. Harrington. 1997. Propagation of native plants for restoration projects southwestern U.S. - preliminary investigations. U.S. Dept. Agr. For. Serv. 77-88.

Farooq, M., S.M.A. Basra, B.A. Saleem, M. Nafees, and S.A. Chishti. 2005. Enhancement of tomato seed germination and seedling vigor by osmopriming. Pakistan. J. Agr. Sci. 42(34):36-41.

Harrison, T.L. and M.R. Berenbaum. 2005. Rutaceaefeeding Agonopterix Hubner (Lepidoptera: Elachistidae) in Illinois. Proc. Entomol. Soc. Wash. 107:162-175.

Harvey, J.H. 1981. A Scottish botanist in London in 1766. Gard. Hist. 9(1):40-75.

Knuth, P. 1908. Handbook of flower pollination. Clarendon Press, Oxford.

Kurz, D. 1997. Shrubs and woody vines of Missouri. Conservation Commission of the State of Missouri, Jefferson City, MO.

Lancaster, R. 1995. Ptelea trifoliata 'Aurea'. Garden 120(1):12-13.

McLeod, K.W. and P.G. Murphy. 1977. Germination ecology of Ptelea trifoliata. Amer. Midl. Nat. 97:363-372.

McMinn, H.E. 1989. An illustrated manual of California shrubs. J.W. Stacey Inc., San Francisco, CA.

Michel, B.E., O.K. Wiggins, and W.H. Outlaw. 1983. A guide to establishing water potential of aqueous two-phase solutions (polyethylene glycol plus dextran) by amendment with mannitol. Plant Physiol. 72:60-65.

Miller, A. and J. Peters. 2010. AOSA/SCST tetrazolium testing handbook. Tetrazolium subcom- mittee of the Assoc. of Official Seed Analysts and the Soc. of Commercial Seed Tech., Fort Collins, CO.

Naglreiter, C., T.G. Reichenauer, B.A. Goodman, and H.R. Bolhar-Nordenkampf. 2005. Free radical generation in Pinus sylvestris and Larix decidua seeds primed with polyethylene glycol or potassium salt solutions. Plant Physiol. Biochem. 43:117-123.

Nokes, J. 2001. How to grow native plants of Texas and the Southwest. Univ. of Texas Press, Austin, TX.

Powell, A.A. and S. Matthews. 1978. The damaging effect of water on dry pea embryos during imbibtion. J. Expt. Bot. 29:1215-1229.

Salehzade, H., M.I. Shishvan, M. Ghiyasi, F. Forouzin, and A.A. Siyahjani. 2009. Effect of seed priming on germination and seedling growth of wheat (Triticum aestivum L.). Res. J. Biol. Sci. 4:629-631.

Scriber, J.M. and R.V. Dowell. 1991. Host plant suitability and a test of the feeding specialization hypothesis using Papilio cresphontes (Lepidoptera: Papilionidae). Great Lakes Entomol. 24(1):27-37.

Sword, G.A. and E.B. Dopman. 1999. Developmental specialization and geographic structure of host plant use in a polyphagous grasshopper, Scistocerca emarginata (=lineata) (Orthoptera: Acrididae). Oecologia 120:437-445.

Tilman, D., P.B. Reich, and J.M.H. Knops. 2006. Biodiversity and ecosystem stability in a decade-long grassland experiment. Nature 441:629-632.

USDA Forest Service. 1948. Woody-plant seed manual. U.S. Dep. Agr. Misc. Publ., Washington, DC.

Yang, E.S.M. and W.L. Applequist. 2015. Phenetic analyses and revised classification of the Ptelea trifoliata complex (Rutaceae). West. N. Amer. Nat. 75:406-428. 